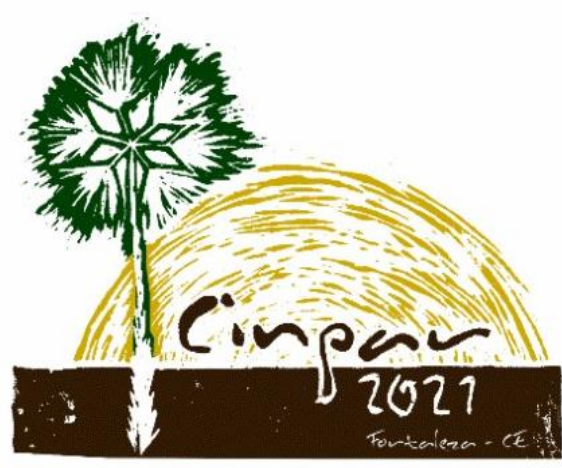

XVII Congresso Internacional sobre Patologia e Reabilitação das Construções

XVII Congreso Internacional sobre Patología y Rehabilitación de las Construcciones

XVII International Conference on Pathology and Constructions Rehabilitation

FORTALEZA (Brasil), 3 a 5 de junho de 2021

https://doi.org/10.4322/CINPAR.2021.087

\title{
Restauração do Patrimônio Histórico de Carlos Drummond de Andrade em Itabira/MG
}

\section{Restoration of the Historical Heritage of Carlos Drummond de Andrade in Itabira/MG}

\author{
Fernanda LELIS MARQUES ${ }^{1}$, Míriam DOS SANTOS PERDIGÃO², Diana Darlen SOARES CANGUSSÚ ${ }^{3}$ \\ ${ }^{1}$ Universidade do Estado de Minas Gerais, João Monlevade/MG, Brasil, fernandamarques05@hotmail.com \\ 2 Universidade do Estado de Minas Gerais, João Monlevade/MG, Brasil, myh_19santos@hotmail.com \\ ${ }^{3}$ Universidade do Estado de Minas Gerais, João Monlevade/MG, Brasil, darlencangussu@gmail.com
}

\begin{abstract}
Resumo: O estado de Minas Gerais é representativo pelo movimento barroco do século XVII e suas respectivas obras literárias e históricas, com construções em talhas, argila, pau a pique e revestimento de ouro. Entre essas obras, a cidade de Itabira abriga o acervo do poeta Carlos Drummond de Andrade. 0 objetivo desta pesquisa é evidenciar a importância de se preservar o patrimônio histórico arquitetônico e a identidade cultural da cidade de Itabira, que está intrinsecamente ligada à imagem de Drummond, com ênfase em uma obra pertencente ao patrimônio histórico local, de relevância regional e global, a Casa de Drummond, por meio de um estudo de caso de intervenções para restauração. Há uma mobilização governamental municipal para manter o acervo original, inserido no contexto histórico da cidade. Foram demonstradas as técnicas construtivas utilizadas, indicadas por meio de manifestações patológicas obtidas em visitas técnicas, com consulta aos projetos, documentação, observações e registros fotográficos. Os resultados mostraram que, através das intervenções, o patrimônio histórico arquitetônico será preservado, resgatando a cultura local, com melhoria no estado de conservação da edificação.
\end{abstract}

Palavras-chave: Itabira. Manifestação patológica. Poeta Drummond.

Abstract: The state of Minas Gerais is representative of the 17th century baroque movement and its respective literary and historical works, with constructions in carvings, clay, stick up and gold plating. Among these works, the city of Itabira/MG houses the collection of the poet Carlos Drummond de Andrade. The research aims to present the case study of interventions for restoration of architectural historical heritage referring to Carlos Drummond de Andrade, in Itabira/MG. There is a municipal government mobilization to maintain the original collection, inserted in the historical context of the city. The construction techniques used in the restorations were demonstrated, indicated by pathological manifestations obtained in technical visits, through consultation of the projects, documentation, observations and photographic records. The results showed that, through the interventions, the architectural historical heritage will be preserved, rescuing the local culture, with improvement in the state of conservation of the building.

Keywords: Itabira. Pathological manifestation. Poet Drummond.

\section{Introdução}

A cidade de Itabira, localizada no estado de Minas Gerais, encontra-se no Quadrilátero Ferrífero, a leste da capital do estado, distando desta cerca de $110 \mathrm{~km}$. O Município é conhecida por ter nascido Carlos 
Drummond de Andrade (1902-1987), poeta modernista, que dedicou parte da sua obra literária à sua terra natal, tendo a representatividade de sua imagem bem vigente mesmo após mais de três décadas de sua morte.

Le Goff (2003) aponta que a memória é um elemento essencial para traduzir a identidade individual ou coletiva, cuja busca é uma das atividades fundamentais dos indivíduos e das sociedades. Algumas vezes, para remeter esta referência ao passado, é necessário construir ou reconstruir bens artísticos e arquitetônicos, visto que os conceitos dos apreciadores destes bens são inconstantes. Manter viva a memória através da preservação das edificações é um fato significativo para a valorização das cidades. Cidadãos que não se identificam com os elementos das cidades tendem a perder o vínculo com as mesmas.

Itabira foi pioneira na proposta de ser um museu a céu aberto, o Museu de Território Caminhos Drummondianos, que tem como objetivo principal possibilitar um maior contato do público com a poesia de Drummond, bem como divulgar o turismo cultural da cidade no Circuito do Ouro e Estrada Real, resgatando a Itabira antiga, por meio das referências encontradas nas obras de Drummond. É a ótica vivenciada pelo poeta em sua especificidade física e em seu contexto poético.

A casa de Drummond, como é conhecido o sobrado onde morou a família Carlos Drummond de Andrade (1902-1987), é uma edificação do século XIX, construído pelo seu bisavó, em estilo colonial mineiro, localizada na região central do município de Itabira. O imóvel possui 32 cômodos, um jardim interno, com canteiros em forma de estrela, meia lua e coração, pintada nas cores azul e branco. A casa segue um padrão lusitano, comum na sua época de construção. O poeta passou os primeiros anos de sua vida nesta casa, sobre a qual ele descreve suas recordações em poemas. Parte integrante do Museu de Território Caminhos Drummondianos. Atualmente, a edificação é tombada pelo patrimônio histórico e utilizado para difundir o trabalho de Carlos Drummond de Andrade e a cultura itabirana.

Itabira é oriunda da extração em grande escala da mineração, essa que, por vez, se torna uma das maiores fontes de renda da população. A Vale S. A. (antiga Companhia Vale do Rio Doce), iniciou suas atividades no ano de 1942, em Itabira/MG. Fato esse, que acarretou no início da exploração do minério de ferro em grande escala na cidade, consequentemente um novo período de desenvolvimento social, econômico e estrutural do município. A mineração, com sua extensão e extração de matéria prima em larga escala, desenvolve cidades com poucos elementos que conectam os cidadãos com um valor simbólico ou uma sensação de pertencimento. Motivos esses, que levou Carlos Drummond de Andrade ser contra a exploração desacertada dos recursos minerais do município, pela Vale S. A.

O objetivo desta pesquisa é evidenciar a importância de se preservar o patrimônio histórico e a identidade cultural da cidade de Itabira, que está intrinsecamente atrelada à imagem de Drummond. A presente pesquisa dará ênfase na obra pertencente ao patrimônio histórico local, de relevância regional e global, a Casa de Drummond, por meio de um estudo de caso de intervenções para restauração, reparação e manutenção desses patrimônios históricos arquitetônicos.

\section{Referencial teórico}

\subsection{O poeta Carlos Drummond de Andrade}

Carlos Drummond de Andrade foi considerado um dos maiores poetas brasileiros do século XX, com um estilo poético de humor, ironia e percepção aguda a cerca da vida cotidiana. Nasceu em 31 de outubro de 1902 em Itabira, interior de Minas Gerais, onde viveu a sua infância e descreve suas recordações em poemas. Filho de proprietários rurais também possuía casa na zona rural, a Fazenda do Pontal.

Dedicou parte da sua obra literária à memória de sua cidade, a casa da fazenda e a que viveu em Itabira, que foi um dos espaços mais importantes na poética drummondiana. De um lado ele enaltecia a cidade, e por outro criticava os efeitos das atividades econômicas de mineração implantada, como: a poluição e a migração 
desordenada (SARAIVA, 2009). Em "Pico do Itabirito", escrito em 1965, ele expressa o sentimento de indignação pela exploração de minério de ferro no local.

Por conta de Carlos Drummond de Andrade, Itabira é reconhecida mais pela cultura do que pela mineração. Saraiva (2009) manifesta que as ações culturais na cidade estão se transformando em um negócio local. É perceptível valorização cultural ligada ao nome do poeta para o desenvolvimento do turismo.

Caminhar pela cidade de Itabira é encontrar Carlos Drummond de Andrade esculpido em seis esculturas de bronze, entre elas a escultura na entrada da Fundação Cultural Carlos Drummond de Andrade (FCCDA), Figura 1. Sua imagem foi também incorporada à paisagem carioca, pois embora mineiro, passou parte significativa de sua vida no Rio de Janeiro. Em 2002 foi comemorado o centenário do poeta, e assim inaugurada uma estátua sobre um banco na orla marítima, no bairro de Copacabana. No monumento, ele está sentado sobre o banco, voltado para a cidade e de costas para o mar, retratando um momento rotineiro onde ele viveu os últimos anos de sua vida.

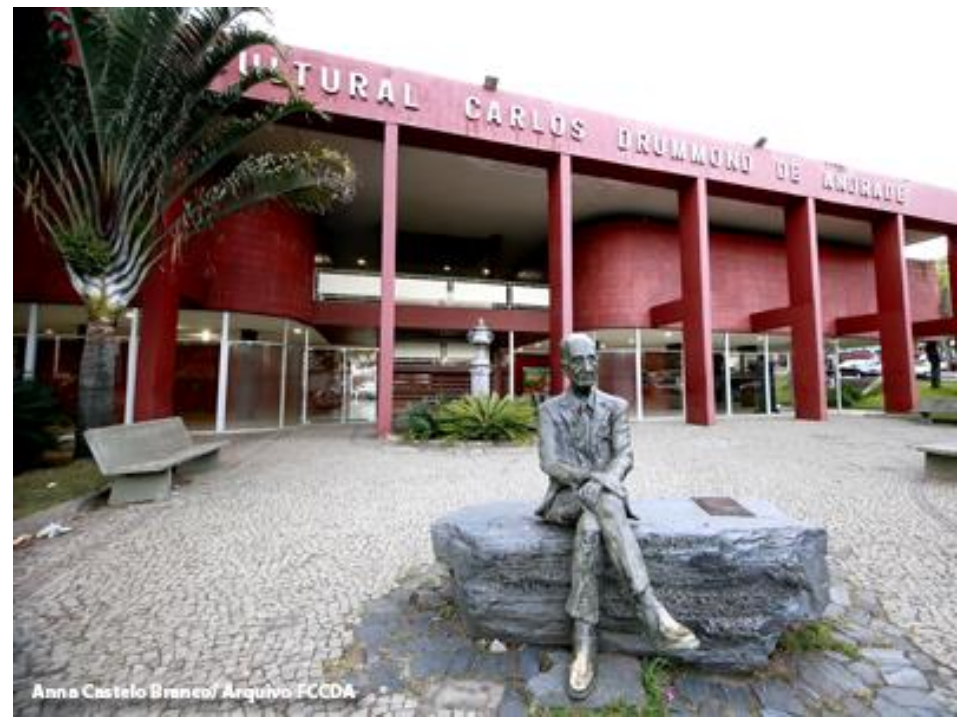

Figura 1 - Escultura de Drummond

\subsection{Casa de Drummond}

A Casa de Drummond, sobrado onde morou a família de Drummond, é uma edificação do século XIX, construído pelo seu bisavô, em estilo colonial mineiro, localizada na região central de Itabira. $O$ imóvel possui 32 cômodos e um jardim interno, pintado em azul e branco. A edificação segue padrão lusitano, comum na sua época de construção. O poeta passou os primeiros anos de sua vida nesta edificação, sobre a qual ele descreve suas recordações em poemas.

A edificação é tombada pelo patrimônio histórico nacional e faz parte do Museu de Território Caminhos Drummondianos, sendo utilizado para difundir o trabalho de Drummond e a cultura itabirana. Os redores da casa, a sua arquitetura, inclusive o jardim e o quintal serviu de inspiração dos diversos e famosos versos do poeta, ao qual trazia as originalidades e traços do local onde residiu por alguns anos, ilustrado na Figura 2.

"Quintal erguido em rampa suave, flores convertidas em hortaliça e chão ofertado ao corpo que adore conviver com formigas, desenterrar minhocas, ler revista e nuvem".

Trecho extraído do poema "Casa", de Carlos Drummond de Andrade. 


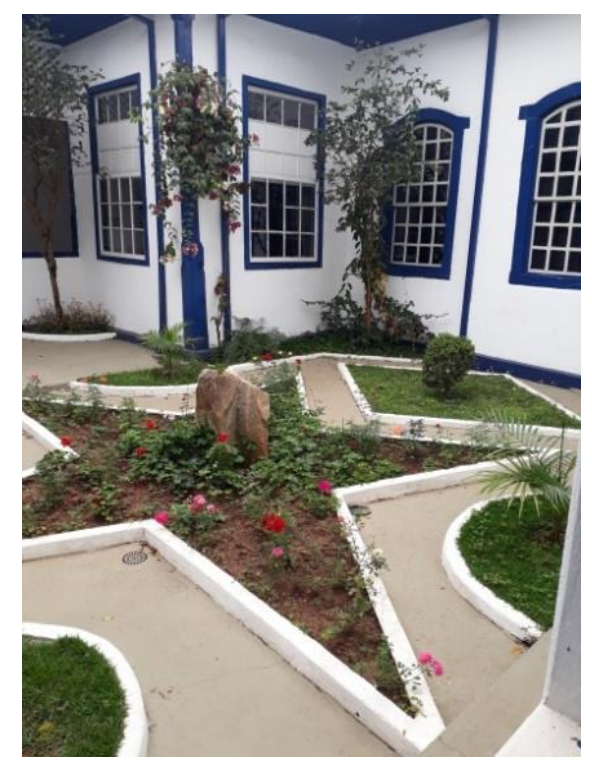

Figura 2 - Jardim da Casa de Drummond

\section{Método de pesquisa}

As informações sobre a restauração, reparação e manutenção do patrimônio histórico arquitetônico referente a Carlos Drummond de Andrade, a Casa de Drummond, em Itabira, foram obtidas decorrente de duas fases:

a) primeira fase: consultas aos documentos disponibilizados pela Diretoria de Estudos e Projetos da Secretaria Municipal de Obras da Prefeitura Municipal de Itabira, como projetos arquitetônicos; projetos de restauração, reparação e manutenção; acompanhados dos documentos: Plano de Trabalho, Planilha de Quantitativos e Especificações Técnicas e Critérios de Medição e Pagamento;

b) segunda fase: visitas técnicas, para observações e registros fotográficos, que colaboraram para os diagnósticos e na indicação de alternativas de recuperação.

\section{Resultados e discussões}

\subsection{A Casa de Drummond}

Para o acervo histórico foram elaborados parâmetros com o objetivo de restabelecer a restauração, reparação e manutenção da edificação, resgatando as características do passado, por se tratar de construção histórica, composta de tijolo e taipa de mão.

Em visitas técnicas foram constatadas presença de umidade, o que resultou nas intervenções de restauração, reparação e manutenção da edificação, conforme presente nos projetos e documentos.

A Casa de Drummond, que já havia passado por outras três restaurações e manutenções, começou a ser restaurada em fevereiro de 2018, com prazo de execução de 60 dias, mantendo o estado original dos elementos construtivos e características arquitetônicas.

As intervenções físicas de restauração feitas na edificação contemplaram a fachada, pintura externa, cobertura, substituição de forros, luminárias e piso, revestimento de alvenaria de vedação, instalações hidráulicas e elétricas. 
A restauração da fachada compreendeu a descupinização para a conservação das estruturas em madeira e a pintura externa, cujas cores escolhidas foram azuis e brancas (Figura 3), seguindo o padrão lusitano da época e em conformidade com o poema "Casa", que relata

Há de ser por fora azul 1911. Do contrário não é casa. (ANDRADE, 2002, p. 917).

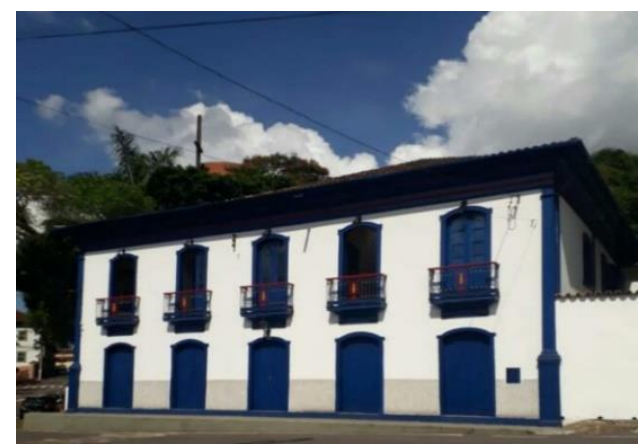

Figura 3 - Casa de Drummond

Em relação ao telhado, as telhas simples de sobreposição, de barro cozido, foram trocadas por telhas capa e canal colonial, com queda de duas águas, colocadas mantendo as direções ortogonais, paralelas às linhas limites da edificação. As telhas e elementos de madeira que apresentaram fissuras, empenamentos ou qualquer outro defeito, não atendendo a NBR 7190 (ABNT, 1997), foram expurgadas.

No caso de telhas terem escorregado e em beirais sem a proteção de forros, as mesmas foram amarradas às ripas com arame de cobre, para evitar a corrosão do mesmo e consequente dano à telha.

Na fixação das calhas pluviais foi utilizada haste metálica zincada, mantendo um espaçamento mínimo entre os suportes, fixando-as nas laterais dos caibros regularmente ao nível dos suportes e sua altura, garantindo assim, a sua declividade.

Foram realizadas as remoções do forro plano de bambu e de madeira, piso (Figura 4-A) e rodapé de madeira, substituindo por outros, com reaproveitamento do material, sendo realizada a pintura no piso e nos rodapés em verniz sintético brilhante, para a sua conservação e proteção de insetos (cupins).

Todas as novas tábuas de madeira eram de boa qualidade, secas ao ar e sem defeitos. Conforme ilustra a Figura 4-B, possuíam as mesmas dimensões, pois foram retificadas à máquina, apresentando superfície aplainada e lixada. Também ocuparam a mesma posição das tábuas substituídas, para viabilizar o seu perfeito encaixe.

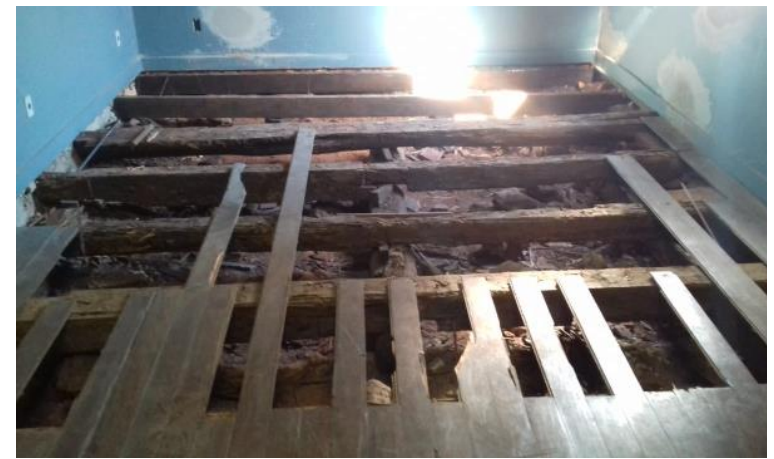

(A)

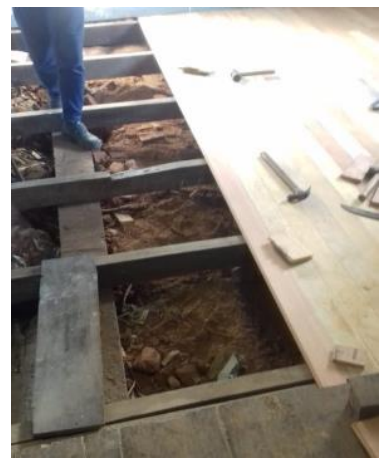

(B)

Figura 4 - Piso de madeira

Restauração do Patrimônio Histórico de Carlos Drummond de Andrade em Itabira/MG 
Foram feitas manutenções nas instalações hidráulicas de água fria e esgoto, com troca de tubos e conexões, como nos ralos, caixas sifonadas de PVC e registros.

Além disso, nas instalações elétricas foram realizados eventuais reparos em diversos pontos de iluminação e tomada, incluindo interruptores simples, trocas de cabos e eletrodutos.

O revestimento na alvenaria, inclusive nas estruturas de concreto e na fachada, utilizou-se argamassa de chapisco convencional de traço 1:3, e por fim realizado a pintura na madeira de esmalte fosco, para a parede tinta látex PVA, ressaltando que em todo momento dos reparos e restaurações houve a preocupação e o cuidado de manter os traços originais.

As paredes compreendem a demolição de revestimento com argamassa (reboco), remoção de pintura antiga, massa única para recebimento de pintura, preparo e pintura interna e externa com aplicação de tinta látex, seguindo as características existentes no local, conforme ilustram as Figuras 5-A e 5-B.

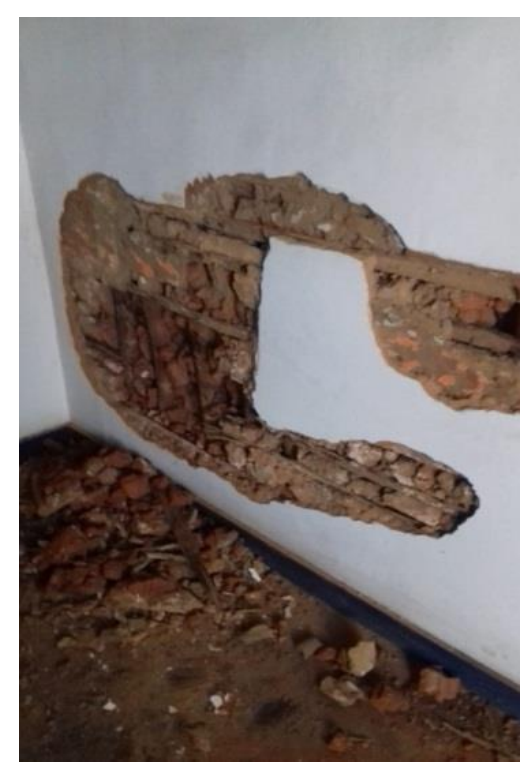

$(\mathrm{A})$

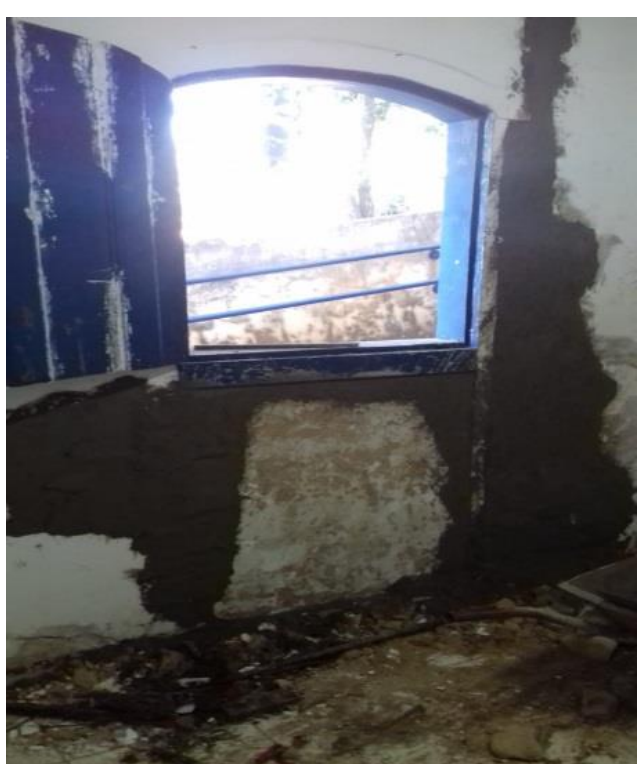

(B)

Figura 5 - Revestimento de alvenaria

\section{Conclusões}

A Casa de Drummond resguardava características originais deterioradas, devido à ação do tempo. Considerando a necessidade de restauração e manutenção, as edificações passaram por intervenções pela Secretaria Municipal de Obras da Prefeitura Municipal de Itabira, ressaltando que houve a preocupação e a prática de manter a integridade e perenidade das edificações e os valores artísticos e culturais.

Os resultados mostraram que, através das intervenções, ficou garantida a preservação de parte do patrimônio histórico de Itabira/MG, mantendo os traços e a originalidade principalmente nas cores, do antigo modelo arquitetonico. Porém, deve-se visar o bom uso das edificações, de forma a garantir a continuidade dos parâmetros de desempenho.

\section{Agradecimentos}

A Secretaria Municipal de Obras da Prefeitura Municipal de Itabira, pela disponibilização de documentos da restauração da Casa de Drummond.

Restauração do Patrimônio Histórico de Carlos Drummond de Andrade em Itabira/MG 


\section{Referências bibliográficas}

ASSOCIAÇÃO BRASILEIRA DE NORMAS TÉCNICAS. ABNT NBR 7190: projeto de estruturas de madeira. Rio de Janeiro: ABNT, 1997.

ANDRADE, C. D. Poesia completa. 3. ed. São Paulo: Nova Aguilar, 2002. 1600 p.

FUNDAÇÃO CULTURAL CARLOS DRUMMOND DE ANDRADE. Espaços culturais. Casa de Drummond. Itabira, 2017. Disponível em: http://www.fccda.com.br/casa-de-drummond/. Acesso em: 01 nov. 2019.

INSTITUTO BRASILEIRO DE GEOGRAFIA E ESTATÍSTICA. Biblioteca. Catálogo. Disponível em: https://biblioteca.ibge.gov.br/biblioteca-catalogo.html?id=450023\&view=detalhes. Acesso em: 23 out. 2019.

LE GOFF, J. História e memória. Tradução: Bernardo Leitão et al. 7. ed. rev. Campinas: Unicamp, 2013. 504 p.

SARAIVA, L. A. S. Mercantilização da cultura e dinâmica simbólica local: a indústria cultural em Itabira, Minas Gerais. 2009. 333 p. Tese (Doutorado em Administração) - Universidade Federal de Minas Gerais, Belo Horizonte, 2009. Disponível em: https://repositorio.ufmg.br/bitstream/1843/BUBD9BDKCV/1/tese_luiz_alex_silva_saraiva.pdf. Acesso em: 07 out. 2019. 